\title{
Breaking Down Barriers to HIV Care for Gay and Bisexual Men and Transgender Women: The Advocacy and Other Community Tactics (ACT) Project
}

\author{
Robin Lin Miller ${ }^{1}$ (I) Jaleah Rutledge ${ }^{1} \cdot$ George Ayala ${ }^{2,3}$ \\ Accepted: 28 February 2021 / Published online: 17 March 2021 \\ (c) The Author(s), under exclusive licence to Springer Science+Business Media, LLC, part of Springer Nature 2021
}

\begin{abstract}
Despite the prevailing consensus on the role that stigma and discrimination play in limiting access to HIV prevention technology, discouraging HIV testing, and impeding access to HIV care, studies that focus on structural interventions to address stigma and discrimination for gay, bisexual, and other men who have sex with men and transgender women are surprisingly uncommon. We aimed to identify the outcomes from a coordinated set of community-led advocacy initiatives targeting structural changes that might eliminate barriers to HIV care for gay and bisexual men and transgender women in five African and two Caribbean countries. We conducted a prospective evaluation that included repeated site visits and in-depth semistructured interviews with 112 people with direct knowledge of project activities, accomplishments, failures, and challenges. Using outcome harvesting and qualitative analysis methods, we observed that over the 18 -month implementation period, local advocacy efforts contributed to enhanced political will on the part of duty bearers for ensuring equitable access to HIV care, increases in the availability of affirming resources, improved access to existing resources, and changes in normative institutional practices to enable access to HIV care. Evidence on Project ACT points to the vital role community-led advocacy plays in addressing stigma and discrimination as structural barriers to HIV care.
\end{abstract}

Keywords Gay · bisexual · and other men who have sex with men · Transgender women $\cdot$ HIV care $\cdot$ Access to care $\cdot$ Structural intervention $\cdot$ Stigma and discrimination $\cdot$ Community-led advocacy $\cdot$ Advocacy evaluation

\section{Resumen}

Estudios cual centran en intervenciones estructurales para abordar el estigma y la discriminación de los hombres gay, bisexuales y otros hombres que tienen sexo con hombres y mujeres transgénero son sorprendentemente poco comunes, a pesar del consenso prevaleciente sobre el rol que desempeñan el estigma y la discriminación al limitar el acceso a la tecnología de prevención del VIH, desalentar las pruebas del VIH e impedir el acceso a la atención del VIH. Nuestro objetivo era identificar los resultados de un conjunto coordinado de iniciativas de incidencia política dirigidas por la comunidad que apuntan a cambios estructurales que podrían eliminar las barreras a la atención del VIH para hombres gay y bisexuales y mujeres transgénero en cinco países de África y dos del Caribe. Realizamos una evaluación prospectiva que incluyó visitas repetidas al sitio y entrevistas profundas semiestructuradas con 112 personas con conocimiento directo de las actividades, logros, fracasos y desafíos del proyecto. Utilizando métodos de recolección de resultados y análisis cualitativo, observamos que durante el período de implementación de 18 meses, los esfuerzos de promoción local contribuyeron a una mayor voluntad política por parte de los titulares de deberes para garantizar el acceso equitativo a la atención del VIH, aumentos en la disponibilidad de recursos afirmativos, mejoras al acceso a los recursos existentes y cambios en las prácticas institucionales normativas

Robin Lin Miller

mill1493@msu.edu

Jaleah Rutledge

rutled72@msu.edu

George Ayala

George.Ayala@acgov.org
1 Department of Psychology, Michigan State University, 316 Physics Road, East Lansing, MI 48824, USA

2 MPact Global Action for Gay Men's Health and Rights, 111 Broadway, Floor 3, Oakland, CA 94607, USA

3 Alameda County Public Health Department, Oakland, CA, USA 
para permitir el acceso a la atención del VIH. La evidencia sobre el Proyecto ACT apunta al papel vital que desempeñan las iniciativas de incidencia política liderada por la comunidad para abordar el estigma y la discriminación como barreras estructurales para la atención del VIH.

\section{Introduction}

Stigma and discrimination are widely considered primary drivers of the disproportionate global burden of HIV on gay, bisexual, and other men who have sex with men and on transgender women ${ }^{1}$ [1-5]. In 2018, UNAIDS estimated gay, bisexual, and other men who have sex with men were at 22 times greater risk of HIV acquisition than members of the general population [6]. Transgender women were estimated at 12 times the risk of HIV acquisition compared with those in the general population. Global estimates further suggest the burden of HIV infection on these populations is increasing, despite broad international commitment to end the HIV epidemic and address the stigma and discrimination that fuels it. The World Health Organization indicates that new HIV infections among "key populations"-gay, bisexual, and other men who have sex with men, transgender women, sex workers, injection drug users-make up an increasingly larger share of all new infections worldwide. In 2018, key populations comprised $54 \%$ of all new infections. By the end of 2019, they comprised $62 \%$ of new infections [7].

Although many countries have made steady progress toward acceptance and inclusion of their sexual and gender minority citizens, others have declined in acceptance or made little discernable progress $[8,9]$. Moreover, gains in acceptance have not necessarily translated into the elimination of structural, interpersonal, and internalized forms of stigma $[10,11]$. Sixty-nine countries still criminalize samesex sexual relations between men; many additional countries criminalize public displays of homosexuality or use "public decency" and similar laws to persecute citizens accused of engaging in same-sex sexual behavior $[9,12]$ and to impede the HIV-focused work of civil society organizations serving sexual and gender minority communities. Stigma and discrimination leveled against gay and bisexual men and transgender women remains pervasive. Whether codified in laws or entrenched in societies' normative beliefs, the impact of antigay/antitransgender prejudice and the stigma,

\footnotetext{
1 Throughout this article, we default to "gay and bisexual men" and "transgender women" as umbrella terms, despite their cultural and linguistic inadequacies and origins as Western descriptors for identity, attraction, and self-expression. For all that these terms lack, they are commonly used among the partners in this project to describe the diverse constituencies on whose behalf the project discussed in this manuscript was conducted. We use the term sexual and gender minority communities to refer to the broader constituencies partnering organizations serve through their other projects.
}

discrimination, violence, and social exclusion to which it leads impacts the day-to-day existence of much of the world's sexual and gender minority citizenry, undermining their safety and overall well-being. Within this broader context, effective strategies to reduce stigma and discrimination and threats to personal safety are urgently needed to eradicate their pernicious effects on HIV vulnerability.

\section{Structural Interventions to Reduce Stigma and Discrimination}

Despite the prevailing consensus on the roles that stigma and discrimination play in limiting access to HIV prevention technologies, discouraging HIV testing, and impeding access to HIV care, studies that focus on structural strategies to address stigma and discrimination for gay, bisexual, and other men who have sex with men and transgender women are surprisingly uncommon. Studies of structural interventions informed by human rights frameworks and deploying advocacy strategies are rarer still. Structural interventions focus on changing distal factors in the social ecology that are presumed as root causes of health inequities or that are theorized to mediate the impact of social-ecological arrangements on health [13]. These interventions generally target political, environmental, economic, cultural, and institutional factors that influence excess risk and vulnerability [14, 15]. Advocacy is an example of a structural intervention.

Structural interventions are inherently political and dynamic processes that reflect underlying systems of values on what is an ideal society and that drives efforts at social change $[13,16]$. Human rights frameworks provide one system of values that underlie structural change advocacy interventions in the public health arena. Advocacy interventions grounded in human rights frameworks aim to facilitate the political agency and civic participation of those whose human right to health are systematically violated, seek redress of human rights violations pertaining to matters of health, and ensure institutional accountability to the protection of citizen's rights to health [17]. In the HIV context, human rights-oriented advocacy interventions are predicated on the assumption that HIV-related health inequalities result from structural impediments to citizens' ability to enact their right to access society's HIV resource infrastructure and participate fully in civic processes to influence the fair and just distribution of HIV resources; they also result from the failure of duty bearers to uphold their responsibilities to ensure complete and equitable access to HIV resources. 
Advocacy strategies vested in human rights frameworks are suited to addressing the barriers to access to HIV care for gay, bisexual, and other men who have sex with men and transgender women and can have enduring effects on their access [18]. However, substantial research gaps exist on what approaches are most promising in removing obstacles to HIV-related resources. There is modest published evidence of how HIV-focused advocacy works as a form of structural intervention and which of its features contribute to progress in promoting access to sensitive and affirming HIV care for gay, bisexual, and other men who have sex with men and transgender women. The dearth of information on structural change linked to advocacy strategies in middle- and low-income countries is greatest. In a recent review covering the 12-year period between 2003 and 2015, Stangl and colleagues identified only 23 investigations of structural interventions-primarily interventions deploying advocacy strategies-designed to increase accessibility, availability, or acceptability of HIV-related resources by targeting human rights-related barriers [19]. Although the authors observed that the vast majority of the studies (86.9\%) lent support to the promise of structural strategies for removing obstacles to care and for creating enabling environments, only one of the 23 interventions sought to address human rights barriers affecting gay, bisexual, and other men who have sex with men and transgender populations, in this case, a sex-worker-led initiative in India. The studies included in the review were also contextually limited. Roughly $30 \%(\mathrm{n}=7)$ were conducted in the USA. Among those conducted in Africa, only three countries were represented, all of which are among the highest-functioning democracies on the continent as ranked in global indices of democratic stability and realization of democratic ideals [20, 21]. Knowledge on successful structural interventions imported from high-income countries may not apply in middle- and low-income countries because of fundamental differences in context (e.g., political governance; pre-colonial, colonial, and post-colonial history; conceptions of human sexual and gender differences). Indeed, it is undoubtedly a mistake to presume the strategies and implementation tactics that work well in high-income democratic settings can be imported in an unmodified form to low- and middle-income countries that operate under different political architectures, legal systems, and cultural norms.

Another recent review [22] examined studies in low- and middle-income countries in which "capacity development" interventions were assessed. In this instance, capacity development was broadly conceived as an effort to enhance the ability of individuals who were members of one or more key populations to claim their human rights and of dutybearing institutions to fulfill their attendant obligations to these rights holders. Thus, the understanding of capacity in this review explicitly orients toward human rights-based advocacy approaches to change. Among these studies, examination of structural outcomes was rare. Most of the studies examined how individual members of key populations changed their knowledge or risk-behavior, violating a key tenet of advocacy: affected populations are not the targets of change other than in their ability to advocate for it [23]. Additionally, few of the studies focused on capacity development strategies aimed at gay and bisexual men or transgender women.

Limited examination of structural interventions to reduce the barriers to HIV care facing gay and bisexual men and transgender women is problematic given the importance of scaling up effective, feasible, and sustainable strategies in country settings excessively burdened by HIV and saddled by stigma and discrimination. Given the significance of context and importance of local relevance for scalability $[13,24,25]$, understanding the contribution of advocacy strategies aimed at structural change to addressing the barriers facing gay and bisexual men and transgender women to care in different low- and middle-income country contexts is imperative. The aim of the current evaluation was to document the intended and unintended outcomes of an advocacy initiative designed to contribute to dismantling structural barriers to HIV care for gay and bisexual men and transgender women in select countries in Africa and the Caribbean. The project aimed at influencing visible decision-making processes, developing leverage on the institutions that control cultural, financial, and other resources related to HIV care access (i.e., institutions in the political, judicial, civic, business, and media arenas), building public support for change, and altering predominant narratives on the issue of equitable access to HIV care for gay and bisexual men and transgender women.

\section{Methods}

\section{Project ACT (Advocacy and Other Community Tactics to Break Down Barriers to HIV Care for Gay and Bisexual Men and Transgender Women)}

Project ACT was a human rights advocacy demonstration project to dismantle structural and social barriers to HIV care for gay and bisexual men and transgender women. The project was conducted over 20-months between June of 2018 and January of 2020 in five countries in Africa (Burundi, Cameroon, Côte d'Ivoire, Ghana, Zimbabwe) and two countries in the Caribbean (Dominican Republic, Jamaica). The project operated on a global partnership model. MPact Global Action for Gay Men's Health and Rights in Oakland, CA, USA (MPact) served as the project's lead implementing partner. MPact is a transnational human rights advocacy organization focused on HIV and sexual health for 
Table 1 Characteristics of Project ACT Countries $(\mathrm{N}=7)$

\begin{tabular}{|c|c|c|c|c|c|c|c|}
\hline & Burundi & Cameroon & Côte d'Ivoire & Dominican Republic & Ghana & Jamaica & Zimbabwe \\
\hline Country population size & 11.9 million & 26.5 million & 26.4 million & 10.8 million & 31 million & 2.9 million & 14.9 million \\
\hline Life expectancy, 2018 & 61 years & 59 years & 57 years & 74 years & 64 years & 74 years & 61 years \\
\hline $\begin{array}{l}\text { Total AIDS cases, } 2018 \\
\text { (Adult prevalence, } \\
15-49 \text { years) }\end{array}$ & $\begin{array}{l}82,000 \\
(1.0 \%)\end{array}$ & $540,000(3.6 \%)$ & $\begin{array}{l}460,000 \\
(2.6 \%)\end{array}$ & $\begin{array}{l}70,000 \\
(.9 \%)\end{array}$ & $\begin{array}{l}330,000 \\
(1.7 \%)\end{array}$ & $40,000(1.9 \%)$ & $\begin{array}{l}1,300,000 \\
(12.7 \%)\end{array}$ \\
\hline $\begin{array}{l}\text { Estimated HIV prevalence, } \\
2018 \text { (gay/bisexual men) }\end{array}$ & $4.8 \%$ & $20.7 \%$ & $12.3 \%$ & $4.0 \%$ & $18.0 \%$ & $29.8 \%$ & $31.0 \%$ \\
\hline $\begin{array}{l}\text { Estimated HIV prevalence, } \\
2018 \text { (transgender women) }\end{array}$ & Unknown & Unknown & Unknown & Unknown & Unknown & Unknown & Unknown \\
\hline Criminalization law & Yes & Yes & No & No & Yes & Yes & Yes \\
\hline $\begin{array}{l}\text { Social acceptance of } \\
\text { LGBTQI rank (out of } 174 \\
\text { countries) }\end{array}$ & 160 & 145 & 127 & 55 & 141 & 93 & 149 \\
\hline Political governance & Authoritarian & Authoritarian & Hybrid & Democratic & Democratic & Democratic & Authoritarian \\
\hline $\begin{array}{l}\text { State democratic fragil- } \\
\text { ity score (possible } \\
\text { range }=0-25 \text { ) }\end{array}$ & 21 & 16 & 17 & 4 & 11 & 3 & 17 \\
\hline
\end{tabular}

We do not identify the names of the Project ACT partner organizations to protect their security

gay, bisexual, and other men who have sex with men and transgender women and on developing the advocacy capacity of fledgling sexual and gender minority community-led organizations around the world. In its role, MPact selected broad strategic objectives for the project, identified a collaborating partner organization in each of the participating countries, and provided collaborating partners with technical assistance and learning exchange opportunities throughout the project's implementation. Each partnering organization was matched with a staff person who provided ongoing support, resources, opportunities, and problem-solving assistance throughout the project's implementation; these staff also leveraged expertise from other Project ACT team members to assist partnering organizations. In some instances, these staff travelled to a partnering organization to provide on-site assistance and support. Partners were sexual and gender minority-focused and led community-based organizations. Although all are publicly visible organizations or emerging as publicly visible organizations within their national contexts, we do not identify these organizations here by name to protect their security.

The countries in which the collaborating partners are based are characterized by poorly managed HIV epidemics among gay and bisexual men and transgender women. Five of the seven countries have among the worst HIV epidemics in the world [6]. Each provides a hostile social and political climate for the human rights of sexual and gender minority people. As displayed in Table 1, four of the countries in Africa are in the bottom quartile of the 174 countries ranked on the William's Institute's scale of societal acceptance of sexual and gender minorities; all five African countries are below the median on this measure [8]. Five have laws criminalizing same-sex sexual relations. The other two criminalize public displays of homosexuality or have public decency laws that are routinely used to intimidate and persecute sexual and gender minority people [9]. Several of the countries are well known for egregious and routine human rights violations [9, 12, 26, 27] and for openly defying international consensus agreements on the human rights of sexual and gender minority people [28]. Not all are considered functioning democracies. Four of the countries are considered fragile states on a standardized measure of government effectiveness and legitimacy [21].

The model of advocacy underlying Project ACT is based on grassroots models of social and structural change practice [23] and on theories of power [29, 30] and community empowerment [31-35]. Taken together, these approaches position advocates as facilitators of a collective effort to pressure and persuade duty bearers to enact and administer policies and practices that are just and equitable. In these approaches, communities are expert on their needs. Developing their capacity to engage in the process of affecting social change is prioritized. Consistent with this approach, the partners in Project ACT chose among three advocacy strategies to increase access to HIV care: challenging policy and legal impediments; reducing stigma and discrimination in health care settings; and eliminating violence and threats to safety and security. Within these three strategies, partners determined which tactics and targets were best suited to addressing obstacles to HIV care within their country context.

Partners created provisional advocacy workplans at the beginning of the project and brought these plans to a 3-day learning exchange workshop held in Cambodia in early June of 2018. During the workshop, the partners presented their 
Table 2 Advocacy tactics used in project ACT

\begin{tabular}{|c|c|}
\hline Primary Tactics Used in Project ACT & Example \\
\hline $\begin{array}{l}\text { Awareness building employed instructional videos, written educa- } \\
\text { tional materials, conferences, and other communication platforms to } \\
\text { highlight to the general public, health care workers, the community, } \\
\text { and others of the human and constitutional rights of gay, bisexual, } \\
\text { other men who have sex with men and transgender women to access } \\
\text { HIV care and to teach members of those communities how to access } \\
\text { their rights }\end{array}$ & $\begin{array}{l}\text { Côte d'Ivoire convinced and trained radio journalists to air programs } \\
\text { addressing the basic human rights of members of the LGBTQI com- } \\
\text { munity and to report on HIV, gay and bisexual men, and transgender } \\
\text { women in an accurate and non-stigmatizing manner }\end{array}$ \\
\hline $\begin{array}{l}\text { Community mobilization organized members of the gay, bisexual } \\
\text { and other men who have sex with men and transgender women's } \\
\text { communities to take leadership in demanding affirming services, } \\
\text { providing information to peers, and engaging in advocacy on behalf } \\
\text { of themselves and others }\end{array}$ & $\begin{array}{l}\text { Zimbabwe trained and deployed } 10 \text { young gay and bisexual men to } \\
\text { mobilize community demand for health care services }\end{array}$ \\
\hline $\begin{array}{l}\text { Documentation involved systematic collection and reporting of data } \\
\text { on violations of human rights, stigmatization, and discrimination in } \\
\text { the provision of care through the use of mystery patients. Documen- } \\
\text { tation often included the development of a system of redress }\end{array}$ & $\begin{array}{l}\text { Cameroon trained } 28 \text { people from the LGBTQI community to act as } \\
\text { mystery patients and record incidents of stigma and discrimination at } \\
\text { major health facilities with high HIV patient loads }\end{array}$ \\
\hline $\begin{array}{l}\text { Policy analysis and engagement included analysis of existing laws } \\
\text { and policies and pending laws and policies from a human rights } \\
\text { framework, with specific attention to how these might affect the } \\
\text { well-being and access to care of gay, bisexual, and other men who } \\
\text { have sex with men and transgender women, and authoring briefs or } \\
\text { otherwise engaging with policy makers on matters of policy reform }\end{array}$ & $\begin{array}{l}\text { Jamaica developed and filed policy briefs on social issues affecting } \\
\text { access to care (e.g., employment, housing) and issued a government } \\
\text { call to action to collect data on transgender citizens }\end{array}$ \\
\hline $\begin{array}{l}\text { Self-stigma reduction used small-group workshops and discussion } \\
\text { forum to help gay, bisexual, and other men who have sex with men } \\
\text { and transgender women build a sense of community, heal from rejec- } \\
\text { tion and stigma, and promote a sense of empowerment and self-love }\end{array}$ & $\begin{array}{l}\text { Ghana offered self-empowerment workshops for gay, bisexual, and } \\
\text { other men who have sex with men and trained them in how to recog- } \\
\text { nize and report human rights abuses }\end{array}$ \\
\hline $\begin{array}{l}\text { Sensitization used small-group workshops and other training formats } \\
\text { to assist targeted audiences such as health care workers become } \\
\text { more knowledgeable on matters of sexual orientation and gender } \\
\text { identification, affirming language and ways of interacting, and } \\
\text { population-specific needs and experiences pertinent to health care } \\
\text { access and sustained health care engagement }\end{array}$ & $\begin{array}{l}\text { Dominican Republic trained providers in seven health care facilities on } \\
\text { affirming care }\end{array}$ \\
\hline
\end{tabular}

choice of strategy(ies) and shared their provisional objectives and workplans. The bulk of the time in the workshop focused on developing a common understanding of advocacy as a structural intervention approach, reviewing the key elements of creating a solid advocacy workplan (e.g., problem analysis, identifying pillars of power, tactic selection, safety and security planning), and engaging in small-group work to refine workplans with assistance and support from the MPact team members. Partners presented their penultimate workplans for feedback on the workshop's final day. Following the workshop, partners created a final workplan. Final workplans relied on using one or more of the tactics described in Table 2. Developing the capacity of fledgling sexual and gender minority-focused organizations was a component of many of the workplans. Several partners (Burundi, Cameroon, Côte d'Ivoire, Jamaica, Zimbabwe) systematically invested in working collaboratively with and developing the capability, visibility, and reputations of smaller organizations.

\section{Design and Data Collection Procedures}

The overall evaluation of Project ACT aimed to address questions regarding the advocacy capacity of the partners, their technical assistance needs, and the evolution in their capacity from participating in the project; document the project's implementation, challenges, and outcomes; explore the role of features of the local contexts on project implementation; and examine the dynamics of the Global NorthGlobal South advocacy partnership. We focus here only on those aspects of the evaluation that pertain to documenting implementation challenges and outcomes. Like other forms of structural intervention, advocacy is notoriously difficult to evaluate [39-45]. Advocacy proceeds dynamically, requiring agile shifts in response to rapid and everchanging circumstances. Implementation is seldom predictable or linear. In a multisite endeavor, as in the case of Project ACT, heterogeneity across contexts is the norm. Designs and evaluation approaches that presume a stable and fixed rather than evolving and changing intervention and a set time frame for changes to emerge poorly suits advocacy. In contrast to 
well-bounded and comparatively simple programs, advocacy seeks to influence complicated multi-level systems in the face of opposition, complacency, and blowback. It is difficult to estimate when and what change to expect, the level at which change might be observed, and how to assign value to steps forward and backward along the way. Failures and setbacks are inevitable and have no bearing on whether the attempt to push for change is worth supporting on ethical grounds or from the perspective of longer time scales than a single evaluation typically permits. The actors who matter in advocacy may not be known in advance. Advocacy relies on the cultivation of networks of actors and development of new champions to a cause. All may contribute to a desired end. Causal attributions to a single actor or activity are often inappropriate if not impossible to make.

The uncertainty and complexity of structural interventions such as advocacy has spurred development of evaluation approaches that rely on reasoning that is neither counterfactual nor attribution focused [46-49]. Rather than rely on establishing change relative to a counterfactual or baseline measure, contribution-oriented approaches assume that many actors and interventions contribute to outcomes in complicated, non-linear, and overlapping ways. These approaches aim to document if and how interventions make a difference in consideration of these other influences and contextual conditions using pattern matching and contribution logics. To evaluate Project ACT, we drew on two contribution-oriented approaches that are readily used in combination to develop a design, measurement, and data analytic strategy. Principles-focused evaluation [50] examines the values-based rules of effective practice necessary to guide action and decision-making in complex and dynamic interventions. In this approach, principles are akin to context-robust and culturally adaptable intervention theory. Outcome harvesting $[51,52]$ is a rigorous method for identifying outcomes when there is uncertainty about what changes to expect, when they might emerge, and how different actors may have contributed to them. Outcome harvesting processes begin with identifying what outcomes have emerged. Using forensic logic, evaluators work backward to connect the evidentiary dots to determine how if at all an intervention has contributed to the outcomes and whether the contributions are substantial or not. Outcome verification occurs by triangulation of source or method. The standard of evidence is similar to the standard of evidence applied in judicial proceedings: the preponderance of evidence beyond a reasonable doubt and strength of the chain of logical, plausible connections.

Consistent with an outcome harvesting approach, for the purposes of this investigation an outcome was defined as a change observed in a person, group of persons, or institution that reflects progress toward (or away from) rights-based access to affirming HIV health care for gay and bisexual men or transgender women and to which Project ACT directly or indirectly contributed. A set of principles of effective advocacy practice were derived through a group collaborative process before data collection began using human rights advocacy and advocacy evaluation literatures [40, 41, 53, 54] and MPact strategic plans, case studies, and annual reports. The 13 principles were used to develop data collection protocols and as part of our data coding framework. A set of 10 principles of effective technical assistance partnerships were also developed and applied similarly. The principles are listed in Table 3.

The overall evaluation of Project ACT employed a qualitatively driven triangulated concurrent longitudinal mixedmethod design $[36,37]$ in which many types of data are gathered from multiple sources at multiple time points. We collected data through multiple means including document reviews, field observations, interviews, surveys, focus groups, and facilitated evaluation exercises using common techniques such as most-significant change storytelling [38]. The data we draw on for the current analyses are qualitative. Most of the data were obtained through routine site visits to the partner organizations located in four of the countries that were followed intensively throughout the project (Cameroon, Côte d'Ivoire, Jamaica, Zimbabwe). These partners were purposively selected to ensure adequate variation in their initial advocacy experience and expertise (range $=8$ to 20 years at the project's outset) and length of history working in collaboration with MPact (e.g., $<2$ years vs. $>2$ years). The four partners were site-visited during the winter of 2018/19 and during the summer of 2019. The third and final set of site visits that were planned to occur after the project had concluded were interrupted by travel restrictions resulting from the SARS-Cov-2 pandemic. Only the partners in Cameroon and Côte d'Ivoire had participated in a final site visit before international travel restrictions were imposed. To the extent possible, data were collected remotely from Jamaica and Zimbabwe via online interviews and email.

Site visit and interview procedures were designed by an evaluation steering committee composed of partner representatives and MPact staff to minimize the possibility that the evaluation might undermine the safety and security of the partner agencies or of respondents. Site visit observations and interviews were planned in close coordination with staff members from the collaborating partner organizations. Visits included observing events, meetings, and activities; touring area health care facilities; holding meetings with representatives of local government and civil society organizations; and conducting private one-on-one and small group interviews with community members, project subcontractors and collaborators, health care workers, and others who could provide insight on project activities and the country's social, cultural, political, legal, and economic context. All site visits and interviews were conducted by RLM. 
Table 3 Project ACT principles of effective technical assistance partnerships and advocacy practice

Technical assistance principles

Leadership_-Nurture others' leadership potential by assisting them gain the skills and experiences required to advocate

Networks-Facilitate mentees' linkages to prospective partners from allied communities, organizations, and institutions

Strategic Focus-Continually create opportunities to engage partners on the project's strategic focus and carrying that focus through to activities

Strengths Orientation-Reinforce and cultivate the existing strengths of those you mentor

Committed Mentoring - Remain available and responsive. Tailor your skill-building and technical support efforts to the needs your mentee articulates and those you observe

Qualified Team-Continually ensure the team possesses the competencies necessary to provide the technical support mentees require

Additional Expertise-Make every effort to supplement the project team with qualified assistance in the areas in which the team has missing or weak competence

Transparency-Communicate truthfully and openly

Respect-Strive to honor and respect the dignity and self-worth of mentees and their constituents. Honor and respect their local knowledge and expertise

Reflection-Engage in critical reflection and team dialogue throughout all phase of project planning, implementation, and closure
Advocacy principles for eliminating barriers to HIV health care access for gay and bisexual men and transgender women

Agility-Capitalize on unexpected opportunities to advance your agenda. Adapt your plans to changes in your environment. Shift tactics to correspond with the moves made and counterstrategies launched by your opposition

Collaboration - Seek out allies with whom you share common cause and partners who complement your strengths. Seek regular opportunities to learn from others' successes, failures, and challenges. Ensure community actions are strong and aligned with actions of allies

Self-care-Engage in healthful self-care routines to protect your own mental and physical health, and to avoid burning out and feeling overwhelmed

Human Rights-Question and challenge fundamental inequalities promoted by mainstream and government institutions. Hold duty-bearers and others who hold power by virtue of their professional role to account for protecting the right to health for all people. Facilitate the participation of all people in society as is their fundamental human right. Leverage the entry points to the laws, policies, and practices that create structural barriers to health care access

Inclusion-Prioritize the needs and concerns of the most marginalized and excluded rather than of the most privileged community members on whose behalf you advocate. Incorporate the perspective of those who are most impacted by oppression and whose rights are most under threat into your advocacy efforts and into the process for setting and revising your agenda

Critical Analysis-Regularly conduct crosscutting political and sociostructural analyses. Choose tactics appropriate to your agenda and analysis of local conditions. Frame languages and messages to suit the local context

Safety-Assess risks to the safety and security of all involved. Make every effort to mitigate those risks. Inform campaign workers and constituents of likely risks and risk mitigation procedures. Identify the probability of backlash and other negative responses to campaigns that might increase constituents' vulnerability in society or set back current efforts. Weigh the probable benefits and costs of planned actions in light of the probability of potential damage to constituents and the larger mission

Reflection-Engage in routine reflection on and re-assessment of strategies and tactics. Create opportunities for dissent and deliberative dialogue with constituents

Evidence-Incorporate the best available evidence from credible sources into campaigns

Access - Strive to remove barriers to HIV-health care for gay and bisexual men and transgender women

Sex Positive-Affirm sex, pleasure, and sexuality as central to sexual health and human well-being

Equity-Pursue actions that promote equity and non-discrimination through mitigating the structural inequalities that disadvantage gay and bisexual men and transgender women. Aspire to recreate society as socially just and fair

Gender-Challenge gender norms, promote the rights and social position of cisgender women and transgender people, and redress power inequities between persons of different genders 
Table 4 Primary data sources

\begin{tabular}{|c|c|c|c|c|}
\hline Stakeholder group & Individual and small-group interviews & Observations & Archives & Surveys \\
\hline MPact & 0 & 0 & 0 & \\
\hline Lead collaborating partners & $\bullet$ & 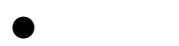 & 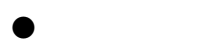 & $\bullet$ \\
\hline Medical community & 0 & 0 & & \\
\hline Government officials & 0 & 0 & & \\
\hline Media & 0 & 0 & & \\
\hline LGBTQI organizations & 0 & 0 & 0 & \\
\hline LGBTQI constituents & 0 & 0 & & \\
\hline Other civil society organizations & 0 & 0 & & \\
\hline TOTAL & 112 interviewees & 68 days & 107 documents & 33 surveys \\
\hline
\end{tabular}

In Francophone countries, interviews were conducted with the aid of a professional translator or a bilingual community member, all of whom were trained in human subjects' research and confidentiality protections. Interviews lasted from $40 \mathrm{~min}$ to $3 \mathrm{~h}$ and $18 \mathrm{~min}$ and were audio-recorded with permission. RLM took field notes of each interview and wrote a comprehensive interview summary after each. All interview respondents provided their informed consent prior to the interview being conducted.

As displayed in Table 4, excluding informal interviews with health care providers, journalists, and government representatives during onsite tours and meetings, 112 people participated in formal semi-structured individual or smallgroup interviews; 24 of these people were interviewed on two or more occasions. Overall, $31.2 \%$ of people interviewed $(n=35)$ were staff members at MPact or one of the seven lead partner organizations, $31.2 \%(n=35)$ were sexual and gender minority community members, $14.3 \%(n=16)$ were staff representatives of civil society organizations collaborating with one of the lead partner organizations, and $14.3 \%$ $(\mathrm{n}=16)$ were health care professionals. The remaining interviewees were journalists $(n=4 ; 3.5 \%)$ or government officials $(n=6 ; 5.3 \%)$. In recognition of the vulnerability of many of the individuals who participated in these interviews, no demographics are provided. Representatives of all of the partner organizations were observed in two face-to-face learning exchange retreats, the first held at the beginning and the second held at end of the project. MPact staff were observed on multiple occasions throughout the project.

The semi-structured interviews were tailored to the stage of project implementation and the respondent and responsive to the ongoing and iterative nature of the evaluation. In general, questions focused on the local political, legal, cultural, economic, and social context; implementation of advocacy activities; application of principles of practice; changes that were occurring (if any); barriers and facilitators to progress; desirable and undesirable occurrences; lessons that were being learned; and perceptions of the global partnership. Outcome harvesting began at the second visit. As the evaluation progressed, the search for and corroboration of outcomes took an increasingly prominent place in the interviews and other site visit activities. During interviews and through other activities (e.g., observing story-telling exercises during the end-of-project workshop held in Rwanda), we identified changes occurring in each country that enabled gay and bisexual men and transgender women to access health care safely and free of discrimination and stigma. We also identified changes that, despite of the best of intentions, weakened, undercut, undermined, or impaired the ability of gay and bisexual men and transgender women to exercise their right to non-discriminatory health care or undermined their safety. We recorded the outcomes to which each partner contributed in an outcome table that documented who and what had changed as indicated by observable behavior. The table included a description of why each observed change was perceived as significant by local actors, specifics of how the project had contributed to the change, and a listing of the sources used to substantiate the outcome and Project ACT's unique contribution (e.g., public and private documents, direct observation, social media analytics, quantitative data collected locally, an independent source). As interviews progressed, respondents contributed novel outcomes to these lists. They were also asked specific questions about outcomes that were not well verified and of which they might have unique knowledge. Any outcomes we could not verify beyond a reasonable doubt were ultimately discarded from the list.

\section{Analyses}

Outcome data were analyzed following the conventions of qualitative evaluative inquiry $[55,56]$. Verified outcomes were entered into an Excel spreadsheet for initial coding. Transcribed interviews, field notes, photographs, and other documents were uploaded to NVivo 11. In the initial stage of coding, RLM elaborated an initial set of 
Table 5 Frequency and percentage of outcomes $(\mathrm{N}=103)$ by category

\begin{tabular}{lll}
\hline Type of change & Definition & Frequency (\%) \\
\hline Consciousness and capabilities & $\begin{array}{c}\text { Skills or actions that demonstrate political consciousness and commitment to the equality of } \\
\text { gay, bisexual, and other men who have sex with men and transgender women }\end{array}$ & $38(36.9 \%)$ \\
Resources & New resources and freedoms or eased access to resources and freedoms & $21(20.4 \%)$ \\
Advocacy capacity & Skills, relationships, resources required to advocate & $17(16.5 \%)$ \\
Agenda setting and dialogue & Coverage, framing, messages, messengers, and new evidence & $12(11.6 \%)$ \\
Norms and practices & $\begin{array}{c}\text { Informal discretionary norms, practices, and structures that drive inequality of access or poor } \\
\text { treatment }\end{array}$ & $12(11.6 \%)$ \\
Formal rules and policies & Formal rules laid down in law or policy or the financial allocations to support their implemen- & $3(2.9 \%)$ \\
& tation & \\
\hline
\end{tabular}

codes through close reading of the outcomes and portions of transcripts in which these were described. RLM developed a preliminary classification system combining attribute codes, magnitude codes reflecting whether outcomes were perceived positively or negatively, and structural codes reflecting advocacy tactics, levels, and sectors of change. Working independently, RLM and JR independently coded all outcomes. The application of these codes was compared, resulting in the revision and reapplication of codes, again each working independently. Coding conflicts were resolved through discussion.

\section{Ethics}

We sought human subjects research approval for the current evaluation from Michigan State University's Social Science Institutional Review Board, which determined the evaluation did not constitute human subjects research (Study ID00001556). Nonetheless, we followed the ethical conventions for human subject research throughout the evaluation, including obtaining informed consent and, as previously noted, observing detailed safety and data security protocols.

\section{Results}

Across the seven collaborating partners, we documented and verified the occurrence of 103 outcomes. Roughly two-thirds $(n=65 ; 63.1 \%)$ of the changes documented occurred to an individual or a small group of individuals and the remaining occurred in institutions $(\mathrm{n}=38 ; 36.8 \%)$. Table 5 classifies these outcomes by the nature of changes observed. As displayed, Project ACT resulted in changes that can be classified into six main types, which we discuss in greater detail below.

\section{Commitments to Equality in Access to HIV Care}

The most common outcome from Project ACT was growth in consciousness and capability to ensure equal access to HIV treatment for gay and bisexual men and transgender women. The project contributed to individuals engaging in specific behaviors that signaled a newfound or enhanced commitment to equal access to HIV care. Signs of their commitment included that leaders of businesses, civil society organizations, and government entities pursued the assistance of Project ACT partner organizations for the first time. These requests to initiate a relationship were typically made in pursuit of partners' expert assistance to accomplish an action such as crafting a new policy to support equitable workplace treatment for sexual and gender minority workers, devising a novel strategy to improve access to resources, or enhancing staff's capabilities to provide affirming treatment. For instance, after having participated in a Project ACT health district sensitization training at the request of their health district director, the heads of the health services in two of Cameroon's largest prisons requested that their entire health services staffs receive sensitization training on affirming service provision. This is a significant local development, as each of the prisons in question have well-documented past records of human rights violations, inhumane and overcrowded conditions, in-prison sexual assault, and poor care of persons living with HIV and of those arrested under Cameroon's homosexuality criminalization laws. The following excerpt from an interview with a local human rights advocate conducted early in the project captures the brutality of these settings and underscores the significance of the unsolicited request for sensitization training:

Two men entered a health care office without identification that they were police. They arrested five people waiting there as patients. Those men spent 8 days in custody, even though the law is that they can only be held for 48 hours. We advocated that they have access to medication, but the police refused, so they 
went without ART for that time. They slept on the floor with one bucket between them. They had unclean water to drink. It broke those guys. It sent fear through the community. We are always afraid. [Human Rights Advocate, Cameroon]

As another example of new consciousness and capability, three health district heads in Cameroon formed a private WhatsApp group to stay abreast of the issues facing gay and bisexual men and transgender women after attending a Project ACT training event. In Côte d'Ivoire, a radio journalist developed a transportation safety protocol to ensure that community members could appear on radio programs without fear of violence on their way to or from his station. His desire to produce the programming and ensure community members' participation in it came as a result of an awareness training that led him to view covering the human rights and health care issues facing the community as his journalistic duty. In some cases, formal agreements arose. In Zimbabwe, for instance, after learning of the project from staff members who worked in a participating health care facility and in anticipation of a national shift toward distributing ART via neighborhood health facilities, the local government's health clinic system pursued a formal Memorandum of Understanding enabling their clinics to join Project ACT. The agreement included provisions for routine sensitization training of health clinic personnel. The desire and willingness of regional and national government entities to sign Memoranda of Understanding with Project ACT was viewed by the Project ACT partners and other local stakeholders as signifying an unprecedented level of commitment to ensure access to care. Approximately two-thirds of the outcomes that reflected growth in consciousness and capability to ensure equal access to HIV treatment resulted from awareness building and sensitization tactics.

\section{Improvements in Access to Resources}

The second most common category of outcomes resulting from Project ACT were improvements in access to HIV care through the creation of new resources or easing of access to existing resources. Roughly $63 \%$ of outcomes reflecting the creation of HIV-related resources or better access to existing resources resulted from strategies in which stigma and discrimination were systematically documented through mystery patient data collection and health care worker sensitization trainings, typically implemented in combination. Although the mystery patient data collection strategies and sensitization trainings were implemented differently in each of the countries that integrated these approaches, the outcomes observed across the countries were similar. New resources evolved in these countries and included the establishment of regular drop-in clinics provided by mainstream health institutions and hosted on-site at trusted sexual and gender minority organizations' facilities. Physicians and mental health providers also offered their services as volunteers to local civil society organizations. These clinics and volunteer arrangements were established after physicians who were exposed to mystery patient data and client testimonials realized the depth of reluctance to seek care from their clinical settings. That gay, bisexual, and other men and transgender women would prefer to die than go to a hospital and be subjected to humiliation was a common refrain in interviews. The following interview excerpt from a patient advocate captures the kind of treatment experiences that drove community members' reluctance to seek services:

I took a young boy with an anal problem-condyloma-to the hospital. He explained the problem to the doctor. The doctor put the boy face down on the examination table. Then he called all of the interns in without the boy's consent to look at him. It was so frustrating. The boy said he would never go back to the hospital. It was a form of violence. [Human rights advocate, Cameroon]

In Ghana, trustworthy facilities in multiple health districts were identified through mystery patient research. These facilities were persuaded to be identified publicly and promoted as safe spaces, expanding the range of options available to gay, bisexual, and other men who have sex with men. In Cameroon, Ghana, and Zimbabwe, targeted facilities took steps to improve their ability to offer affirming care. These steps included participating in systems of ongoing community feedback and redress and developing facilityspecific corrective action plans. Exposure to mystery patient data documenting stigma and discrimination was integral to prompting corrective action. As one interview respondent noted, the data highlighted "patterns to hospital administrators and health care workers that they would not otherwise be able to observe." A physician respondent referred to these data as a "call to conscience". In Cameroon, health care workers and officials were presented with the quantitative findings of 162 covert mystery patient observations. They also heard accounts from two of the data collectors on their experiences collecting those data. In the following excerpt from an interview with a physician at a large hospital, the physician recounts the impact of being exposed to the data and the stories told of collecting it. The mystery patient who is described in this excerpt is one of the transgender women enlisted to collect data:

She told a story of being in a hospital waiting room seated between two pregnant women. The women shifted away from her. They whispered to one another, moving, that they were fearful their unborn children might catch the same disease. They preferred to stand. 
She told another story of being laughed at by a nurse who, after seeing her, went to get her co-workers from the back to come out. They stood in the doorway and stared and laughed. She had to call on all of her strength to stay there in the face of repugnant treatment. The nurse had the wrong attitude. She asked stupid questions. "Are you a man or are you a woman?" She replied, "Why can't I be myself?" That made me ask myself "What can I do to enable access?" It moved me. [Physician, Cameroon]

Another respondent, after remarking that "statistics establish facts" and that the mystery patient data established for her both the presence of homosexuality in Africa and the presence of stigma and discrimination in her health care facility, observed:

The data regarding the mystery clients was alarming. If ever I ask my health care staff if they stigmatize or discriminate, they say "no!" They are not aware of what they are doing. Only through training and the testimonials did it allow them discovery. The data clearly showed patients experience stigma and discrimination and that they may not go to get care because of it. It is not easy for them. The mystery clients, for them it was their first time to claim their right to access care. The training was an opportunity to listen to their grievances and to learn about their experiences. It was more impactful than the statistics. Discussing the things that made them not want to go to facilities. How staff punish them. Making them wait in the queue. Exposing them. Mocking them. That is not in the statistics. The figures I saw for my district made me ashamed because as a health care provider, I ought to provide care to all patients regardless of their sexual orientation. [Health care administrator, Cameroon]

Health care workers in Ghana and Cameroon took personal initiative to create stopgap mechanisms for gay, bisexual and other men who have sex with men and transgender women to avoid having to spend long periods of time in waiting rooms and to enable them to obtain ART prescriptions in private settings rather than having to queue at the pharmacy. These mechanisms included allowing their cellphone numbers to be distributed in the community by mystery patients so that gay and bisexual men and transgender women could directly call physicians to bypass the waiting rooms or distributing ART from their homes. Although not all of the mechanisms these health care workers created reflect sustainable, systemic solutions, the small steps they took remain significant as they demonstrate a newfound willingness to act on the belief that it is unacceptable for people to leave a health care facility without care because of negative experiences in or on the way to the waiting room, during an examination, in the pharmacy, or while interacting with a security guard, patient registrant, or payment clerk. Health care workers were also actively planning more permanent solutions. For instance, several Cameroonian facilities are developing new patient orientation videos and other waiting room materials to emphasize to all patients that their clinic or hospital adheres to non-discrimination policies and that it is a human and constitutionally guaranteed right of all national citizens to receive care. Ghanaian nurses are devising a protocol for re-engaging clients who dropped out of care.

\section{Strengthened Capacity to Advocate}

Project ACT contributed to enhancement in the advocacy capacity of partnering organizations and individuals within them. In Côte d'Ivoire, for instance, a remotely located civil society organization that focuses on sexual and gender minorities partnered with the project to make nine small media videos, several of which documented gay and bisexual men's experiences of being denied health care services, rejected by their families, and targeted for violence. These videos came to the attention of a mainstream national human rights organization. The two organizations subsequently developed an alliance to ensure wider attention to the human rights issues faced by people residing in rural sexual and gender minority communities. Establishing a new partnership with a mainstream ally opens the possibility of new avenues for advocacy and increased opportunities to influence institutions and systems that affect access to HIV care. It also lends legitimacy to the work performed by the constituency-led sexual and gender minority organization. In Burundi, the Project ACT partner evolved an infrastructure among seven smaller constituency-led organizations for documenting information on human rights violations in health care provision and seeking redress, strengthening the capacity of these groups to advocate on a national scale. In Jamaica, transgender people were coached through the process of participating in the Universal Periodic Review on Jamaica's human rights record and on shadow reporting, which led in turn to the first transgender-specific submission from Jamaica to a treaty body at the United Nations. The cultivation of partnerships was a vital part of the development of organizations' capacity, whether those occurred with mainstream civil society or human rights organizations, health care facilities, government actors, popular local performers, or others.

At the individual level, community members gained and began to apply advocacy-related skills beyond the project. For instance, in Cameroon, a constituent-led organization used their data collection training as mystery patients to develop and implement their own project to map violent hotspots around their city and develop a community 
violence warning system for their members. In multiple countries, the activities that comprised the project built a base of person-power necessary for facilitating a social movement around sexual and gender minority rights. A focus group of 9 young men in Zimbabwe had an animated discussion on how they now "enter spaces proudly" and know "what to say and how to say it" to mobilize and build an advocacy base centered on their rights. Early in their exchange, one young man captured the sentiment of the group when he exclaimed "We now have armor against homophobia." Zimbabwe's peer mobilizers were instrumental in mobilizing 453 gay and bisexual men to demand health care services and in preparing gay, bisexual, and other men who have sex with men to report instances of stigma and discrimination. Their efforts drove an increase in service use at a local facility up by over $300 \%$ in a single quarter, according to clinic records. They also took the initiative to write abstracts on their work that were accepted for presentation at International Conference on AIDS and STIs in Africa (ICASA) 2019. One mobilizer spoke on a youth-focused panel about criminalization as a hurdle to sexual and reproductive health care services for sexual and gender-diverse youth. Three parliamentarians attended his session, two from Uganda and one from Sierra Leone. After the session, two of these policy makers requested his advice on how to improve their country environments for sexual and gender minority youth. One of the Ugandan parliamentarians requested his ongoing consultation on how to ensure the safety of sexual and gender minority delegates to ICASA 2021. Attracting the attention of highlevel duty bearers and evolving relationships to them can ensure that politicians are attuned to the challenges faced by sexual and gender minority communities in accessing health care and cultivate them as advocacy champions of the communities' human rights.

Individuals, after participating in Project ACT activities, asserted their claim to human rights through actions such as filing police reports, resisting attempts at blackmail, and engaging in self-advocacy. Rights holders claiming their rights and openly sharing their identity normalizes their presence in police stations and other institutions and provides community members with positive role models. Individuals within health care systems also gained advocacy capacity. For instance, in Zimbabwe nursing staff who underwent training to become Project ACT advocacy champions devised a plan to push for sensitization training to become a standard part of the curriculum in one of the largest nursing training programs in the western region of the country. Overall, skills gained through the process of learning to document stigma and discrimination, intentional efforts to mobilize the community, and efforts to reduce self-stigma were the primary contributors to the vast majority $(81 \%)$ of advocacy capacity outcomes.

\section{Dialogues, Raised Awareness, and Action-Driven Agendas}

Project ACT led to increases in the coverage and framing of issues pertinent to access to health care and human rights. In Jamaica, for example, Project ACT partners drafted a call to action in which they demanded the Jamaican government document transgender experiences as part of its routine data collection efforts. The call was presented at a Transgender Health and Wellness Conference. The call to action was picked up by the Jamaica Observer, a national newspaper, and featured in a story in its July 1, 2019 edition. Jamaica's Project ACT partner also wrote a policy brief that contributed to a motion introduced into Parliament to lift restrictions on abortion. Although the connection to HIV care may seem far, Jamaica's Offences Against the Person act lists abortion in articles 72 and 73 and criminalizes same-sex sexual behaviors in articles 76 through 79 . The motion led to parliamentary discussions on privacy, autonomy, and individual rights as these pertain to health care. As one respondent explained,

the media took it up and that led to a decriminalization conversation about abortion....If we can get parliamentarians to talk about human rights and health, we can mainstream discussion of LGBTQ issues. [Human Rights Advocate, Jamaica]

In Côte d'Ivoire, gay and bisexual men appeared as guests on several radio programs, allowing them the opportunity to craft a narrative on the normalcy of sexual and gender minority people and make a public case for their human right to access health care and live free of violence. Reflecting the experiences of other journalists who produced on-air programs on health, human rights, HIV, and sexual and gender minority communities, the attention his initial programs garnered, as indicated by calls to the station, surprised him and his supervisors:

I made one show as an audition and was finally permitted to produce three on gay men. The first received enough calls that management accepted me doing two more. The initial calls were negative, but the second and third got more positive reactions. [Radio journalist, Côte d'Ivoire]

Project ACT led to the generation of new evidence of mistreatment in attempts to access health care, which was used to set action agendas for health care facilities in Cameroon, Ghana, and Zimbabwe. In these countries, evidence of mistreatment in the provision of health care provision also set the agenda for subsequent sensitization efforts. Awareness building efforts, such as the conference where the reporter heard the call to action, contributed to a sizeable minority $(42 \%)$ of these outcomes. 


\section{Changed Norms and Practices}

The project resulted in informal changes to exclusionary practices and norms. Examples of these changes ranged from sanctioning and retraining of health care workers who were documented to have engaged in an act of discrimination to placing new affirming and welcoming signage in clinics. For instance, in Ghana after community members were trained to report inappropriate behaviors on the part of health care professionals to a redress system, a group of nurses and a pharmacist were discovered to have disclosed private patient information on HIV status to people outside of their workplaces. These instances were reported back to the appropriate facilities through the Project ACT redress system developed by the Ghanaian partner. In response, these providers were reprimanded. One was fired. These actions on the part of the supervisors in these facilities signal the intent to serve gay and bisexual men and transgender women respectfully. Documentation and sensitization strategies contributed to $84 \%$ of documented informal changes in norms and practices.

\section{Policy Shifts}

In a small number of instances $(n=3)$, outcomes occurred as formal policies. For instance, in the Dominican Republic, the Ministry of Health signed a two-party Memorandum of Understanding that guarantees health care workers' attendance at sensitization trainings and establishes a national training calendar. In Jamaica, a community-based organization that serves vulnerable youth drafted its first-ever policy on transgender youth. In Zimbabwe, a clinic established a policy that all new employees regardless of their position must undergo sensitization training. No one tactic was dominant in the development of formal policies.

\section{Undesirable Outcomes}

Although undesirable outcomes were also observed, these were a minority of outcomes $(n=9 ; 8.7 \%)$. Many of these undesirable consequences occurred for an individual or small group of individuals and concerned their loss of safety and security or access to resources. In two cases, individuals who participated in self-stigma reduction activities that were part of mobilizing service demand experienced a loss of personal resources after seeking to claim their rights or honor their identities. In one case, an individual was jailed after calling the police to report he was being harassed over his sexuality. In the other, a minor transgender youth suffered the loss of family support and access to basic resources, including housing, food, and tuition. She had permitted herself to be photographed as her preferred gender during an event that she had learned about through a Project ACT self-stigma reduction session. The photo was circulated in her neighborhood and to her family, causing her to flee home for her safety. Although she has since secured stable housing and can meet her basic needs, describing the loss of daily interaction with her mother and grandmother in her interview reduced her to tears. A similar negative consequence occurred for a person who agreed to be the subject of a small media video produced for the project; its unexpected popularity had made it an unwelcome intrusion in her life.

Other undesirable outcomes occurred among health care workers and radio personnel. In these instances, negative outcomes included increased workplace tension among colleagues, retrenchment and rejection of project messages, and enduring stigma and derision from other workers due to their open support of gay, bisexual, and other men who have sex with men's and transgender women's equality of access to care. For instance, health care providers were stigmatized by colleagues for attending sensitization trainings in Cameroon. A health care worker in Zimbabwe accused her colleagues of accepting "dirty money" for attending sensitization trainings for which they received transportation reimbursement. Some health care workers in Zimbabwe claimed gay and bisexual men were expecting "special" and "red carpet" treatment, deflecting attention away from the fact the treatment these men receive is often poor. One respondent observed:

The school of physicians felt too much attention was being placed on gay and bisexual male clients. They reject all of this emphasis on pronouns as complicating their work. They claim they know how to serve their clients. [Human rights advocate, Zimbabwe]

He went on to note that some health care workers did not believe the community members knew the difference between poor care and stigmatizing or discriminatory treatment, creating pressure on advocates to ensure the validity of their mystery patient data in order to protect the credibility of their efforts. Radio hosts reported they were shunned and stigmatized by colleagues for putting sexual and gender minority people on air. One journalist, after describing his supervisor's staunch opposition to his effort to produce programming and her eventual decision to put the weight of responsibility for going forward solely on him, leaned across his radio console and pointed his finger toward the studio's lobby: "I was stigmatized by that guy you saw at the entrance for doing this. Colleagues treat me differently."

In only one case was an undesirable outcome observed at an institutional level. In Cameroon, several sexual and gender minority-led organizations stopped referring clients to a private clinic with a favorable reputation after their mystery clients consistently recorded negative experiences there. For example, one described the following: 
Before going to the [government hospital], I prepared myself to face difficulty. But I was actually really disappointed by the treatment I received at [private clinic with good reputation]. First, when I got in the hallway, no one welcomed me. I sat in the waiting room. They asked me about what problem I had come there for in front of others in the waiting room. I asked for HIV screening. The counseling was poor. I went into the lab. They have a logbook with the test results of all the patients. It was open so I could see the names and the results. When my results came back, they told them to me in front of others. The results were not sealed. I was not offered post-test counseling. People came in and out during the blood draw. [Mystery Patient, Cameroon]

Notably, the mystery patient data collected in Cameroon provide support for the perception that the private clinic's reputation as being better than the other health care institutions to which it was being compared is undeserved. Mystery patients confirmed that the places were simply not that different when it came to how they were treated.

\section{Discussion}

Eliminating the excess burden of HIV on gay and bisexual men and transgender women requires scalable and feasible structural interventions that can break down the barriers to HIV care resulting from entrenched stigma and discrimination. We sought to contribute to the modest empirical literature on structural interventions designed to eliminate HIV service barriers for gay and bisexual men and transgender women by documenting the implementation and outcomes of a novel multi-country advocacy demonstration project carried out in five African and two Caribbean countries. Prospective longitudinal evaluations of interventions such as this are rare. We believe exploring how advocacy works to address structural factors that restrict access to HIV care and that are driven by stigma and discrimination adds useful information to the emergent base of evidence on these types of interventions in low- and middle-income country contexts.

Consistent with the limited body of evidence pointing to the importance of community-led advocacy for addressing structural barriers to HIV-related services [19, 57], we observed meaningful gains in creating a more enabling environment for accessing HIV care in each participating country. Specifically, we identified nearly 100 changes, big and small, to which advocacy made a positive contribution. This is undoubtedly an underestimate, as we did not have the opportunity to investigate and verify outcomes for three of the projects through site visits and because of our inability to collect data for a third and final time in Jamaica and Zimbabwe. The number of changes we identified is noteworthy given the very brief time frame over which the advocacy activities were supported and the overall hostility of the national contexts toward sexual and gender minority people in which these efforts were made. Our evaluation points to the importance of supporting community-led advocacy and to investing in robust evaluations of these efforts to build a base evidence on the design, implementation, and outcomes of structural interventions to improve access to HIV care for gay and bisexual men and transgender women in low- and middle-income country contexts.

Each of the tactics that partnering organizations deployed were associated with positive outcomes, although the types of outcomes commonly associated with each tactic differed. As others have observed [57], community monitoring tactics played a central role in fostering environments of accountability and encouraging greater awareness among people who hold positions of power on the impact of their action (or inaction) on access to HIV care for gay and bisexual men and transgender women. Variations on mystery client documentation and community sensitization tactics, often used together, prompted concrete efforts on the part of health care administrators and workers to work more closely with the community to improve access and to re-examine local institutional policies and practices. Institutions made concrete uses of the data gathered by the community. The mystery client documentation strategy coupled with sensitization and systems of redress produced especially noteworthy outcomes. The synergistic effects of structural inventions when combined should be further explored.

We found tactics to address self-stigma were important precursors to building demand for services and preparing community members to engage in public facing activities. Individuals who participated in self-stigma activities routinely indicated it was quite novel in their country context to have access to interventions to challenge internalized stigma, affirm the value of who they are, and foster their mental health. Stigma-reduction activities proved vital to helping these community members understand their rights and to enabling them to engage in advocacy actions with confidence. Mystery patients described their training and fulfillment of their role similarly. Community psychologist Isaac Prilleltensky characterizes what these participants gained as a psychological sense of mattering [58]; the experience of feeling valued and of adding value. He argues that feeling valued and having opportunities to add value are fundamental to well-being and capacity for social action. In the contexts where these kinds of activities were not part of the effort or were implemented in limited fashion, their absence was universally viewed as a problematic oversight. Structural interventions with gay and bisexual men and transgender women may benefit from being coupled with 
activities to address self-stigma and self-care to ensure that advocates feel well-supported to fully embrace their tough roles as rights holders who are challenging the duty bearers who hold power over their ability to claim their rights.

Structural interventions to advance the human rights of gay and bisexual men and transgender women face unique challenges including politicized homophobia and other forms of social and state-organized backlash [59-66]. In these data, we observed absence of political will on the part of government or other actors who could leverage support and participation slowed the work dramatically or forced major revisions to how the work moved forward. Wellfounded community fear of violence also challenged the work. In places such as Côte d'Ivoire, for example, fear impeded the radio journalists who had become allies to the project from easily recruiting people as guests to their programs. Structural interventions that fail to take this context into account run a high risk of undermining rather than furthering the goal of dismantling stigma and discrimination and may endanger local communities $[59,60,63,64$, 67-69]. A major tenet of the approach to this project was deference to local understanding of what adaptations and approaches were best and how to implement those in ways that were safe. Partners' evolving adaptations were often made in response to safety concerns. Negative outcomes, though rare, all pertained to safety and security. Although some of these outcomes might be unavoidable, such as inviting stigma from colleagues for championing the cause of gay and bisexual men and transgender women, the proactive development of plans and strategies to address safety and security are required in challenging contexts in which stigma, discrimination, violence, and criminalization are of particular concern. These could include emergency response planning with stakeholders (e.g., in-country UNAIDS offices), emergency funding sources, and contingency plans for shelter and relocation.

\section{Limitations}

The results of our evaluation must be considered in view of its limitations. Although we can provide an in-depth examination of what these advocacy initiatives accomplished and how they were carried out, we could not document each of the initiatives with equal intensity due to budgetary constraints on the evaluation. The four countries that we examined closely shared much in common with those we were not able to study intensively, but neither do they perfectly reflect their experiences. In Burundi, for example, staff were actively surveilled by the police throughout the project and were unable to assemble constituents for meetings without risking arrest. No other partner was required to shape their activities and practices in response to similar circumstances. The creative adaptations that the Burundians made to develop a digital system of redress in the face of such hostility are not fully captured in these data. Second, in each country, partners determined the persons whose perspectives would be most useful to obtain, with guidance from the evaluation's steering committee. Although in every country those we spoke with provided diverse views on the initiative and candidly pointed to its strengths and limitations, we cannot be sure we captured the full range of perspectives on the merits and failings of the initiative. Third, because we were unable to complete the final longterm follow-up in two of the countries as we had planned, we have a less comprehensive picture of final months of work in Zimbabwe and Jamaica. Zimbabwe's ongoing economic struggles and problems with power supply and basic infrastructure made obtaining data under the conditions of lock down virtually impossible, as too few people have functioning internet capability and consistent access to power in their homes. Nevertheless, one strength of our evaluation is that we were able to visit countries repeatedly and interview informants in each country at more than one point in time, which provided us with a rich understanding of how the initiatives changed over time in response to implementation and environmental challenges.

\section{Conclusion}

Evidence on Project ACT points to the vital role community-led advocacy plays in addressing stigma and discrimination as barriers to HIV care. Resources to support interventions often favor individually focused, ameliorative interventions over those that have the potential to produce structural change. Structural interventions are chronically under-funded and, with few exceptions, seldom supported for sufficiently long time periods to realize their benefits. Additionally, failure to prioritize program evaluation and implementation science studies of structural interventions has contributed to a dearth of information on these interventions in low- and middle-income contexts [22], despite the critical role these interventions might play in improving access to services and promoting accountability to human rights imperatives. Although we provide a limited glimpse into Project ACT here, our evaluation data provides a rich picture of advocacy's implementation and outcomes and points to critical areas for future investigation of communityled structural interventions to break down the barriers that prevent gay and bisexual men and transgender women from accessing HIV care.

Acknowledgements The authors gratefully acknowledge the staff at each of the partnering organizations for their assistance in planning and carrying out site visits and in serving on the evaluation's advisory 
committee. We are also grateful to the members of the USA-based Project ACT: Omar Banos, Stephen Leonelli, Nadia Rafif, Mohan Sundararaj, Greg Tartaglione, and Johnny Tohme. Volunteer transcription assistance was provided by Sarah Alabdali, Danielle Chiaramonte, Maeve Denshaw, Gabrielle Grace, Brynn Muelenberg, Alexandra Pawlaczyk, Sarah Raider, Rachel Weber, Cameron Wilson, and Fangzhou $\mathrm{Xu}$. Interviews conducted in Francophone countries were assisted by translators Melodie Bamén, Alassane Touré, and Raymond Young. French translations of evaluation instruments were performed by Jack Wehyrich and Jean Kayitsinga. Spanish translations of evaluation instruments were performed by David Figueroamartin and Tatiana Bustos. Additional translation assistance was provided by Angel Fabian.

Funding Project ACT was funded by the LGBT Fund, a partnership of the Elton John AIDS Foundation, the United States President's Emergency Plan for AIDS Relief through the Office of the Global AIDS Coordinator, and UNAIDS, through a grant awarded to MPact Global Action for Gay Men's Health and Rights. The evaluation was commissioned by MPact Global Action for Gay Men's Health and Rights.

\section{Declarations}

Conflict of interest The authors declare that they have no conflict of interest.

Ethical Approval All procedures performed in studies involving human subjects were in accordance with ethical standards of the institutional and/or national research committee and with the 1964 Helsinki declaration and its later amendments of comparable ethical standards.

Informed Consent Informed consent was obtained from all individual participants included in the evaluation.

\section{References}

1. Beyrer C, Baral SD, Collins C, Richardson ET, Sullivan PD, Sanchez J, Trapence G, Katabira E, Kazatchkine M, Ryan O, Wirtz AL, Meyer KH. The global response to HIV in men who have sex with men. Lancet. 2016;388:198-206.

2. Dunbar W, Labat A, Raccurt C, Sohler N, Pape JW, Maulet N, Coppieters Y. A realist systematic review of stigma reduction interventions for HIV prevention and care continuum outcomes among men who have sex with men. Int J STD AIDS. 2020;31:712-23.

3. Kane JC, Elafros MA, Murray SM, Mitchell EMH, Augustinavicius JL, Causevic S, Baral SD. A scoping review of healthrelated stigma outcomes for high-burden diseases in low- and middle-income countries. BMC Med. 2019;17:1-40.

4. Santos GM, Do T, Beck J, Makofane K, Arreola S, Pyun T, Herbert P, Wilson PA, Ayala G. Syndemic conditions associated with increased HIV risk in a global sample of men who have sex with men. J Sex Transm Infect. 2014;90:250-3.

5. Valdiserri RO, Holtgrave DR, Poteat TC, Beyrer C. Unraveling health disparities among sexual and gender minorities: a commentary on the persistent impact of stigma. J Homosex. 2019;66:571-89.

6. UNAIDS. UNAIDS Data 2019. Retrieved from: https://www. unaids.org/sites/default/files/media_asset/2019-UNAIDS-data_ en.pdf; 2020.

7. World Health Organization. HIV/AIDS fact sheet. Retrieved from: https://www.who.int/news-room/fact-sheets/detail/hiv-aids; 2020.
8. Flores AR. Social acceptance of LGBT people in 174 countries, 1981 to 2017. Los Angeles: UCLA School of Law Williams Institute; 2019.

9. Mendos LR. State-sponsored homophobia 2019. Geneva: International Lesbian, Gay, Bisexual, Trans and Intersex Association; 2019.

10. Hatzenbuehler M. Structural stigma and the health of lesbian, gay, and bisexual populations. Curr Dir Psychol Sci. 2014;23:127-32.

11. Hatzenbuehler M, Rutherford C, McKetta S, Prins SJ, Keyes KM. Structural stigma and all-cause mortality among sexual minorities: differences by sexual behavior? Soc Sci Med. 2020;244:112463.

12. International Lesbian, Gay, Bisexual, Trans and Intersex Association. Maps - sexual orientation laws. https://ilga.org/maps-sexualorientation-laws; 2020.

13. Parkhurst JO. Structural approaches for prevention of sexually transmitted HIV in general populations: definitions and an operational approach. J Int AIDS Soc. 2019;17:19052.

14. Blankenship KS, Bray SJ, Merson MH. Structural interventions in public health. AIDS. 2000;1(4):S11-21.

15. Gupta GR, Parkhurst JO, Ogden JA, Aggleton P, Mahal A. Structural approaches to HIV prevention. Lancet. 2008;372(9640):736-75.

16. Parkhurst JO. HIV prevention, structural change, and social values: the need for an explicit normative approach. J Int AIDS Soc. 2012;15(suppl. 1):17367.

17. London L. What is a human-rights based approach to health and does it matter? Health Hum Rights. 2008;10(1):65-80.

18. Tempalski B, Beane S, Cooper HLF, Friedman SR, McKetta SC, Ibragimov U, Williams LD, Stall R. Structural determinants of Black MSM HIV testing coverage (2011-2016). AIDS Behav. 2020;24:2572-87.

19. Stangl AL, Singh D, Windle M, Sievwright K, Footer K, Iovita A, Mukasa S, Baral S. A systematic review of selected human rights programs to improve HIV-related outcomes from 2003 to 2015: What do we know? BMC Infect Dis. 2019;19:209.

20. Marshall, MG, Etzinga-Marshall, G. Global report 2017: Conflict, governance, and state fragility. Center for Systemic Peace. http:// www.systemicpeace.org/vlibrary/GlobalReport2017.pdf; 2018.

21. The Economist Intelligence Unit. Democracy index 2019. https:// www.eiu.com/topic/democracy-index; 2020.

22. Kiragu M, Fonner VA, Munyuwiny S, Izulla P, Pantelic M, Restoy E, Eiling E, O'Reilly KRO. Does capacity development increase demand for health services and rights among key populations affected by HIV? A systematic review of evidence from low and middle-income countries. AIDS Behav. 2020;24:2268-81.

23. Alinsky SD. Rules for radicals: a pragmatic primer for realistic radicals. New York: Vintage; 1971.

24. Miller RL, Shinn M. Learning from communities: overcoming difficulties in the dissemination of prevention and promotion efforts. Am J Community Psychol. 2005;35:169-83.

25. Miller RL, Outlaw A. From discovery to applications: challenges in effectiveness and implementation research for the promotion of LGBTQ health and wellness. In: Stall R, Dodge B, Bauermeister JA, Poteat T, Beyrer C, editors. LGBTQ health research: theory, methods, practice. Baltimore: Johns Hopkins University Press; 2020. p. 260-86.

26. Human Rights Watch Country Profiles. https://www.hrw.org/ video-photos/interactive/2018/04/16/sexual-orientation-genderidentity-country-profiles; 2020.

27. United States Department of State. 2019 Country profiles on human rights practices. Available at: https://www.state.gov/repor ts-bureau-of-democracy-human-rights-and-labor/country-reportson-human-rights-practices/; 2020.

28. Namwase S, Jjuuko A, editors. Protecting the human rights of sexual minorities in contemporary Africa. Pretoria: Pretoria University Law Press; 2017. 
29. Prilleltensky I. Understanding, resisting, and overcoming oppression: towards psychopolitical validity. Am J Community Psychol. 2003;31:195-202.

30. Prilleltensky I. The role of power in wellness, oppression, and liberation: the promise of psychopolitical validity. J Community Psychol. 2008;36:116-36.

31. Fedi A, Mannarini T, Maton KI. Empowering community settings and community mobilization. Community Dev. 2009;40:275-91.

32. Maton KI. Empowering community settings: agents of individual development, community betterment, and positive social change. Am J Community Psychol. 2008;41:4-21.

33. Zimmerman MA, Eisman AB. Empowering interventions: strategies for addressing health inequities across levels of analysis. In: Bond MA, Serrano-García I, Keys CB, Shinn M, editors. APA handbook of community psychology: methods for community research and action for diverse groups and issues. Washington, D.C.: American Psychological Association; 2017. p. 173-91.

34. Zimmerman MA. Empowerment theory: psychological, organizational, and community level of analysis. In: Rappaport J, Seidman E, editors. Handbook of community psychology. New York: Kluwer; 2000. p. 43-63.

35. Zimmerman MA. Psychological empowerment: issues and illustrations. Am J Community Psychol. 1995;23:581-99.

36. Creswell JW, Plano Clark VL. Designing and conducting mixed methods research. 2nd ed. Thousand Oaks: Sage Publications; 2011.

37. Clark VLP, Ivankova NV. Mixed methods research: a guide to the field. Thousand Oaks, CA: Sage Publications; 2016.

38. Davies R, Dart J. The 'most significant change' (MSC) technique: A guide to its use. Author; 2004.

39. Arensman B. Advocacy outcomes are not self-evident: the quest for outcome identification. Am J Eval. 2020;41(2):216-33.

40. Gardner AL, Brindis CD. Advocacy and policy change evaluation: theory and practice. Stanford: Stanford University Press; 2017.

41. Schlangen R. Monitoring and evaluation for human rights organizations: three case studies. Washington, D.C.: Center for Evaluation Innovation; 2014

42. Teles S, Schmitt M. The elusive craft of evaluating advocacy. Stanf Soc Innov Rev. 2011;9:39-43.

43. United Nations Evaluation Group Human Rights and Gender Equality Task Force. Integrating human rights and gender equality in evaluation: towards UNEG guidance. New York: United Nations; 2011.

44. Arensman B, van Wessel M. Negotiating effectiveness in transnational advocacy evaluation. Evaluation. 2018;24:51-68.

45. Van Wessel M. Narrative assessment: a new approach to evaluation of advocacy for development. Evaluation. 2018;24:400-18.

46. Gates E, Dyson L. Implications of the changing conversation about causality for evaluators. Am J Eval. 2016;38:29-46.

47. Mayne J. Contribution analysis: coming of age? Evaluation. 2012;18:270-80.

48. Patton MQ. A utilization-focused approach to contribution analysis. Evaluation. 2012;18:364-77.

49. Schwandt TA. Evaluation foundations revisited: cultivating a life of the mind for practice. Stanford: Stanford University Press; 2015 .
50. Patton MQ. Principles-focused evaluation: the guide. New York: Guilford Press; 2018.

51. Wilson-Grau R. Outcome harvesting: principles, steps, and evaluation applications. Charlotte: Information Age Publishing; 2019.

52. Wilson-Grau R, Britt H. Outcome harvesting. Cairo: Ford Foundation; 2012.

53. Raynor J, York P, Sim S. What makes an effective advocacy organization? A framework for determining advocacy capacity. Los Angeles: California Endowment for the Arts; 2009.

54. Reisman J, Gienapp A, Stachowiak S. A guide to measuring advocacy and policy. Baltimore: Annie E. Casey Foundation; 2007.

55. Patton MQ. Qualitative research and evaluation methods. 4th ed. Thousand Oaks: Sage; 2015.

56. Saldana J. The coding manual for qualitative researchers. 3rd ed. Thousand Oaks: Sage Publications; 2016.

57. Baptiste S, Manouan A, Garcia P, Etya'ale H, Swan T, Jallow W. Community-led monitoring: When community data drives implementation strategies. Curr HIV/AIDS Rep. 2020;17:415-21.

58. Prilleltensky I. Mattering at the intersection of psychology, philosophy, and politics. Am J Community Psychol. 2020;65:16-34.

59. Currier A. Out in Africa: LGBT organizing in Namibia and South Africa. Minneapolis: University of Minnesota Press; 2012.

60. Currier A. Politicizing sex in contemporary Africa: homophobia in Malawi. London: Cambridge University Press; 2019.

61. Currier A, Cruz JM. Civil society and sexual struggles in Africa. In: Obadare E, editor. The Handbook of civil society in Africa. New York: Springer; 2014. p. 337-60.

62. Currier A, McKay T. Pursuing social justice through public health: gender and sexual diversity activism in Malawi. Crit Afr Stud. 2017;9:71-90.

63. Epprecht M. Heterosexual Africa? The history of an idea from the age of exploration to the age of AIDS. Athens: Ohio University Press; 2008

64. Epprecht M. Sexual minorities, human rights, and public health strategies in Africa. Afr Aff. 2012;111:223-43.

65. Miller RL, Reed SJ, Francisco VT, Ellen JM. Conflict transformation, stigma, and HIV-preventive structural change. Am J Community Psychol. 2012;49:378-92.

66. Miller RL, Reed SJ, Chiaramonte D, Strzyzykowski T, Spring H, Acevedo-Polakovich ID, Chutuape K, Cooper-Walker B, Boyer $\mathrm{CB}$, Ellen JM. Structural and community change outcomes of the Connect-to-Protect Coalitions: trials and triumphs securing adolescent access to HIV prevention, testing, and medical care. Am J Community Psychol. 2017;60:199-214.

67. Corey-Boulet R. Love falls on us: a story of American ideas and African LGBT lives. London: Zed Books; 2019.

68. Mulé NJ. LGBTQI-identified human rights defenders: courage in the face of adversity at the United Nations. Gend Dev. 2018;26:89-101.

69. Thomann M. HIV vulnerability and the erasure of sexual and gender diversity in Abidjan. Cote d'Ivoire Glob Public Health. 2016;11:994-1009.

Publisher's Note Springer Nature remains neutral with regard to jurisdictional claims in published maps and institutional affiliations. 